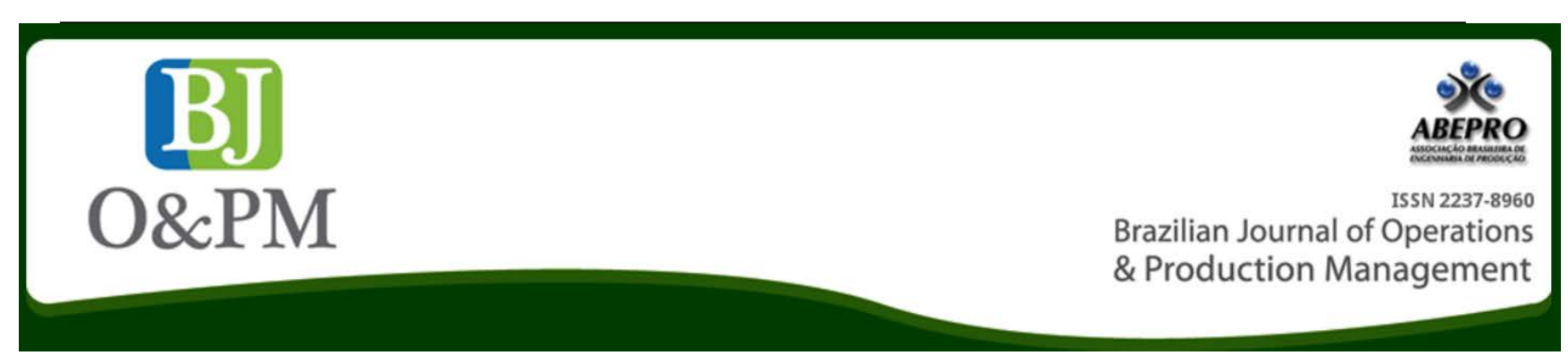

\title{
PROJECTS AND OPERATIONS IN THE OIL AND GAS E\&P SEGMENT: A BIBLIOGRAPHIC PANEL
}

\author{
Jose Francisco Tebaldi de Castro ; Claudio Benevenuto de Campos Lima ${ }^{a}$; Ruben Huamanchumo Gutierrez ${ }^{\mathrm{a}}$ \\ ${ }^{\text {a }}$ Federal Fluminense University (UFF) - Niterói, RJ, Brasil
}

\begin{abstract}
This article provides a better understanding from the literature on the multi-disciplinary processes management and on large critical projects, in multiple environments, in an oil operator. A bibliographic panel was prepared, from a bibliometric research, focusing on portfolio, projects, operations and resources. The analysis of the literature was made from the perspective of integration of processes, taking as fundaments their interdependencies and multidisciplinary aspects. There was no evidence that integration is a reality in processes so large and multi-disciplinary, as well as in multiple environments with large projects. However, good practices were found and they are related to isolated cases. This study identified and separated issues that are inherent to the studied processes, from the ones that are result of poor integration and immaturity of the processes which are of vital importance for the construction of an integrated and multidisciplinary model. This article takes a critical look on how the treatment of such aspects add value through the identification of the interfaces, that are important in organizations that operate in multiple environments projects, together with production operations.
\end{abstract}

Keywords: Portfolio, Multiple Projects, Integrated Planning, Resource Management

\section{INTRODUCTION}

Resource allocation is a complex task, where many techniques are used in order to obtain the best combination of projects within a portfolio and hence sort them ensuring the expected results. Resources can be dedicated, usually originating from partnership contracts, but can be also shared and relocated when and where need. This work presents what was available in the literature on the management of resources considered critical for the management of a portfolio, consisting of multiple and large projects in line with the operational management in the exploration, development and production maintenance segment of an oil company. Thus a critical look at the concepts presented by several researchers was developed, based on a bibliometric analysis and a literature research.

Project management, its applications in the oil and gas industry as well as the portfolio and the associated resources have been frequent objects of academic and professional research. However, it is clear that there is still little research on the production operation which is based on the use of shared resources with multiple project portfolios. Thus, it is important to consider the reduced number of publications on the subject, which invariably affects restrictively the guidelines in a decision-making involving the covered areas. It is mandatory to understand the meaning of "integration" between these processes, since they are very comprehensive and multidisciplinary. There is still much to be researched on what should be integrated and how to do it.

Considering the scope described above, the present paper intends to present the current understanding available on some processes considered critical in a company and find approaches in the researched material on how to integrate them. For this, it was necessary to create a bibliographic panel on the portfolio management, projects, resources and production operation processes, based on the reflections brought by the authors researched, developed from themes in published articles, books, journals and other academic bases. Following, it is presented the methodology to better develop this discussion.

\section{RESEARCH METHODOLOGY}

Considering its nature, the research typology is associated with the production of knowledge that will answer 
Brazilian Journal of Operations \& Production Management

Volume 12, Número 2, 2015, pp. 306-320

DOI: 10.14488/BJOPM.2015.v12.n2.a10

questions related to the oil and gas industry. This research can be defined as bibliographic according to Vergara (2011). It can also be classified as qualitative exploratory, with an inductive approach, as defined by Gutierrez (2010) and shown in Figure 1.
The proposed research can be considered as scientific, starting with a real literature sample to a broader generalization. For this, formal points of view were considered, registered in the investigated texts, not considering other characteristics, such as social and human.

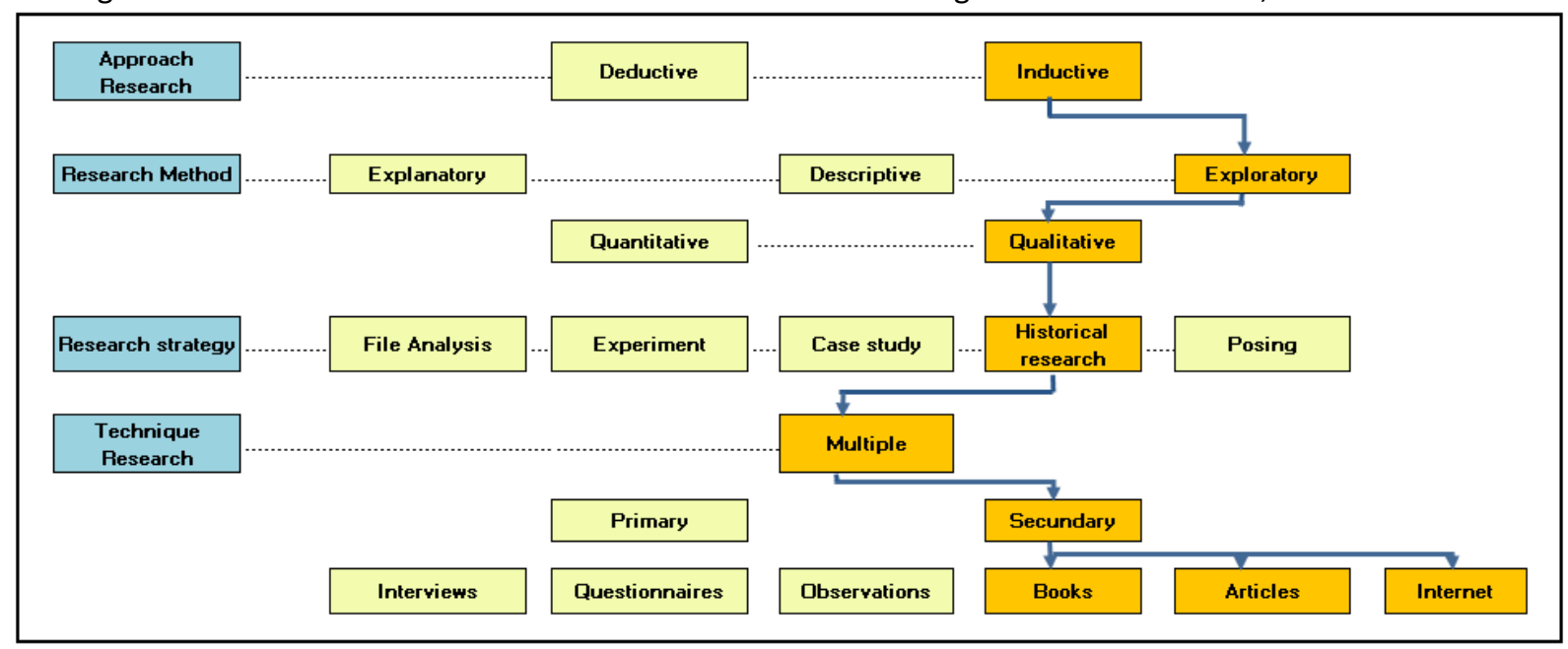

Figure 1-Methodology

Source: Adapted from Gutierrez (2010)

In this way, based on the extraction of several texts from the literature, new reflections came from concepts already established in the academic field, related to the described processes management. Thus, this study was classified as qualitative exploratory, since it considers the previously discussed topics, looking for similarities with theories about the addressed processes, by making them more explicit and explanatory, according to Gil (2010). As a complement, the method considers different interpretations of the authors surveyed, in order to understand the relationships between processes and add new points of view. As described by Gil (2011):
"[...] the data analysis in experimental researches and in surveys is essentially quantitative. This does not happen, however, with researches classified like field studies, case studies, action-research and participant research. In these, analytical procedures are mainly qualitative. "

This work is also bibliographic, multiple tactics, using the survey on secondary sources such as books and monographs, dissertations and theses, and articles published in specialized technical journals. Considering the methodology described above and in order to reach a greater methodological rigor and higher reliability in the qualitative analysis, the roadmap presented in Figure 2 was followed.

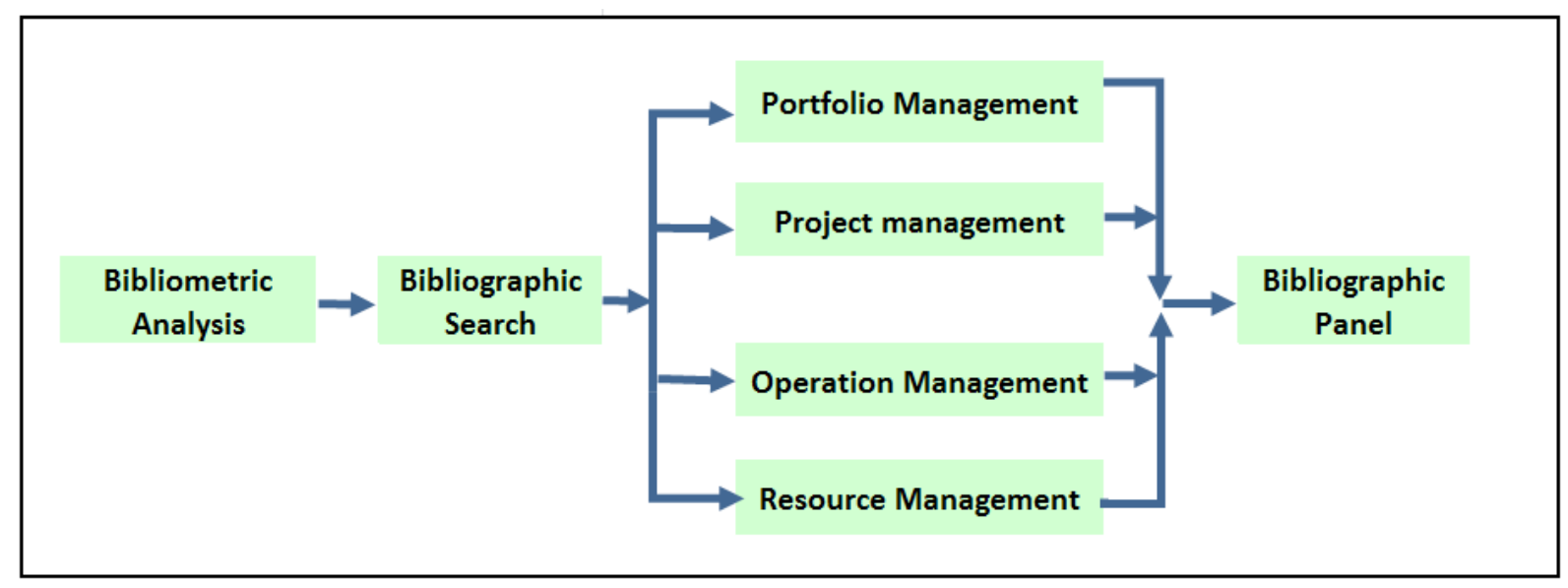

Figure 2 - Research Roadmap 
The bibliometric analysis is detailed in the next item. It was necessary to find literature that could present any association with the themes and also to focus on research areas and specific markets. The bibliometric analysis was based on shared resources of management processes as well as portfolio management and project management in oil and gas area.

Figure 2 shows that the literature research was structured in the various sources of a literary content, in order to bring information about the processes under review. For this, however, keywords and groups of words were used, which will be presented in bibliometric analysis. The bibliographic research was conducted, then, based on the structure of the results presented in bibliometric analysis.

Finally, a Bibliographic Panel, product of this research, allowed the creation and ordering of the literature statements, related to four major processes, i.e., as they occur, in the view of the authors surveyed. It was also possible to build new concepts, from the statements. The Bibliographic Panel is shown in next in this paper.

\section{BIBLIOMETRIC ANALYSIS}

The beginning of this work took place in 2012 when it was decided to make previously a bibliometric analysis, considering the little literature about the processes addressed, regarding the issues of integration and interfaces identification between them. Thus, the bibliometric analysis was carried out between September and October 2012, considering the following initial formation of words for the search: ALL (portfolio resources commitments OR project portfolio management OR gerenciamento de portfolio), through Scopus database, which has good coverage in the area of interest (Energy - oil and gas). The period searched was between 1960 to the present day, in all fields, but looking only for articles. The research found 1912 results.

A new research was developed, in which areas of interest related to Health Sciences, Life and Social Sciences were removed, restricting to the Exact Sciences, focusing on Engineering, Chemistry, Energy, Computer Science, Mathematics, Physics and Environmental Science. Then, 893 results were found. The sample was submitted to another restriction. This time, limiting the number of journals that usually publish articles focused on topics of interest. A number of 242 results were found, available for more than 14 journals, with the largest number of published articles. This was the final size of the sample studied.

It was preceded to the bibliometric analysis as explained by Costa (2010): "The survey of authors with the most publications within the subjects searched, and the chronology of publications". Observing the Graph 1, there is a growing and continuous acceleration in the production of articles, from the 2002, with a concentration between 2010 and 2012. Part of this growth is due to the great interest in the knowledge search related to the management portfolio, in multiple environments and large projects. It is also possible to infer that the intersection between portfolio, projects and resources management are a recent subject.

The main affiliations and publications, by country and by main thematic areas were also taken from the research, indicated in the sample, where the authors are concentrated. It is observed in Figure 3 that the theme "Energy" shows percentually still a very small contribution $(8.5 \%$ of the sample). Business and Engineering Management account for $41 \%$ of the results.

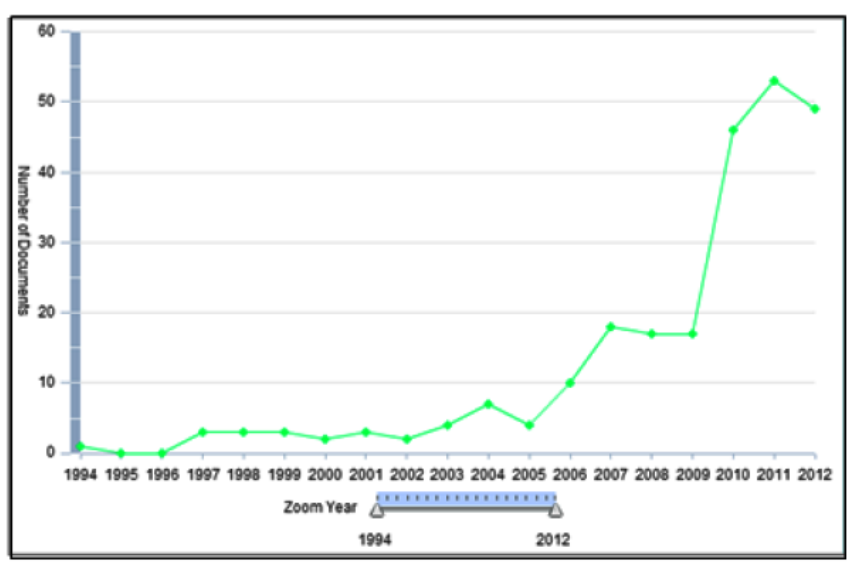

Graph 1 - Number of published articles over the time From: the authors

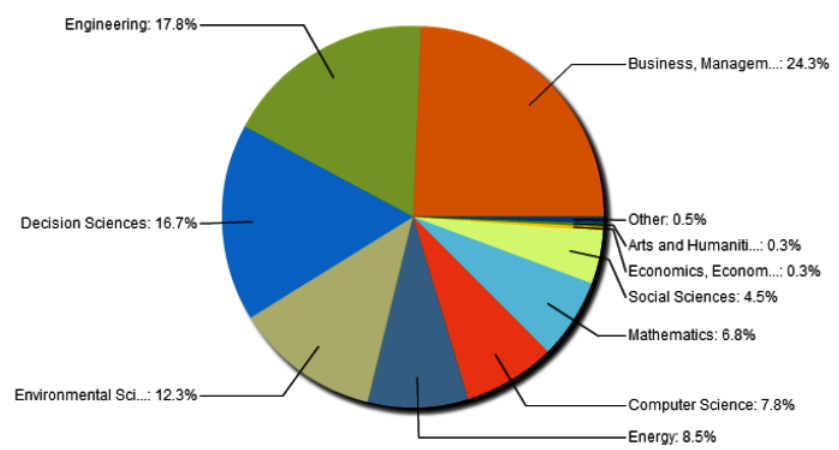

Figure 3 - Thematic Areas

From: the authors

For the initial selection of the articles, the classifications were followed, according to Costa (2010):

a)thesixolderpublications, withthefirstcurrents ofthought; b) the ten most recent articles by different authors, present in the surveyed base to capture the different currents of thought; c) the five most cited articles in Scopus, within the sample considered; 
d) the ten most relevant articles according to the Scopus criteria; e) the most relevant publications for the cycles identified in Graph 1. Thus, the periods were selected between 1994 and 2002, 2003 to 2005, 2006 to 2009 and between 2010 and 2012.

From there, 26 publications were then obtained, that formed the basic core of the literature, as shown in Table 1. It is emphasized that the bibliometric analysis was made only in Scopus, which brought very up-to-date publications, which shows that.

There are many publications dedicated to project management, result of a strong standardization from the 60 s and, more strongly, from the creation of the PMI in the US and other equivalent organizations in other countries. There is also a lesser extent of articles focused on portfolio management, where there was a higher production from 1990s and a concentration from 2010. With respect to resource management, this research brought a small amount of publications of supply chain, Theory of
Constraints and even suppliers. At the time of bibliometric analysis, publications dedicated to the production operation management were not objective of this search, because, at that moment, the operational management was seen as a separate issue from portfolio management. As the bibliographic research was being developed, the operation management was realized as an integral and fundamental part of the interfaces analyzed.

\section{BIBLIOGRAPHIC RESEARCH}

After the bibliometric analysis, over 2013 and in accordance with Valle, Gutierrez et Costa (2013), as well as Scopus, other important bases were consulted, like Engineering Village, ScienceDirect and Scielo, including also direct searches on the Internet. In order to obtain the best results, the keywords in Table 2 were used, which also presents the related results in each round of the searches.

\begin{tabular}{|c|c|}
\hline Item & Artigos escolhidos para comporem o núcleo basico da pesquisa bibliográfica \\
\hline 1 & ARCHER, N. P. et al. A decision support system for project portfolio selection. Pp. 105-114. 1998. \\
\hline 2 & AHLEMANN, F. Towards a conceptual reference model for project management information systems. Pp. 19-30. 2009. \\
\hline 3 & $\begin{array}{l}\text { CANIELS, M. C. J. et al. The effects of Project Management Information Systems on decision making in a multi project environment. Pp. } 162-175 \text {. } \\
2012 .\end{array}$ \\
\hline 4 & $\begin{array}{l}\text { DA SILVA, E.M. et al. Critical Chain of the Theory of Constraints applied to Executive Engineering Project Management: A case study in a petroleum } \\
\text { refinery. Pp 1-16. 2012. }\end{array}$ \\
\hline 5 & DE BAKKER, K. et al. Does risk management contribute to IT project success? A meta-analysis of empirical evidence. Pp. 493-503. 2010. \\
\hline 6 & DE CASTRO, H.G. et al. Project portfolio management: An exploratory study on the challenges of its implementation and results. Pp $283-295.2010$. \\
\hline 7 & $\begin{array}{l}\text { DE TREVILLE, S. et al. From supply chain to demand chain: The role of lead time reduction in improving demand chain performance. Pp. } 613-627 \text {. } \\
2004 \text {. }\end{array}$ \\
\hline 8 & GHASEMZADEH, F. et al. Project portfolio selection through decision support. Pp. 73-88. 2000. \\
\hline 9 & HALLGREN, M. The Construction of research questions in project management. Pp 804-816. 2012 \\
\hline 10 & HEISING, W. The integration of ideation and project portfolio management - A key factor for sustainable success. Pp. 582-595. 2012. \\
\hline 11 & KILLEN, C. P. et al. Understanding project interdependencies:The role of visual representation, culture and process. Pp. 554-566. 2012. \\
\hline 12 & $\begin{array}{l}\text { LASLO, Z. Project portfolio management: Na integrated method for resource planning and scheduling to minimize planning/scheduling-dependent } \\
\text { expenses. Pp. 609-618. } 2010 \text {. }\end{array}$ \\
\hline 13 & LASLO, Z. et al. Resource allocation under uncertainty in a multi-project matrix environment: Is organizational conflict inevitable? Pp. $773-778.2008$. \\
\hline 14 & MESKENDAHL, S. The influence of business strategy on project portfolio management and its success - A conceptual framework. Pp. $807-817.2010$. \\
\hline 15 & $\begin{array}{l}\text { MONTIBELLER, G. et al. Structuring resource allocation decisions: A framework for building multi-criteria portfolio models with area-grouped } \\
\text { options. Pp. 846-856. 2009. }\end{array}$ \\
\hline 16 & PADOVANI, M. et al. Portfolio of projects: Case study of selection and balancing. Pp 157-180. 2010. \\
\hline
\end{tabular}




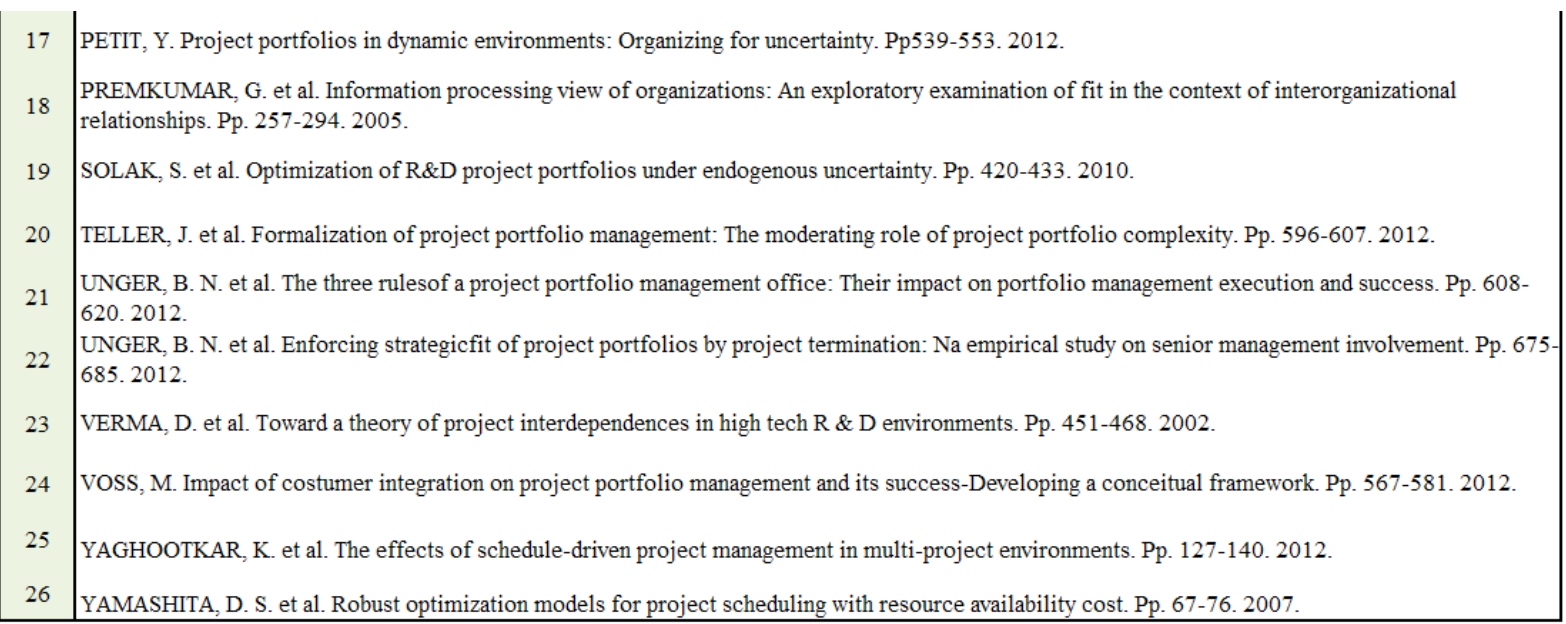

Table 1 - Publicações do núcleo básico da pesquisa

Source: The authors own.

The results used after the search refinements are also presented in Table 2, restricting to 242 results in Scopus, 121 in Engineering Village, 233 in ScienceDirect and 55 in Scielo, totaling 651 results. A second analysis of the same bases had 59 results, 26 articles from Scopus (basic core of the research), 8 in Engineering Village, 20 in ScienceDirect and 5 in Scielo. Then, a final analysis was performed, more careful, adding a collection of 51 articles and conference papers, 19 of Scopus from the bibliometric survey, conducted in October 2012 (basic core of the research), 7 in Engineering Village 20 in ScienceDirect and 5 in Scielo, as shown in Figure 4.

\begin{tabular}{|c|c|c|c|c|}
\hline \multicolumn{5}{|c|}{ Consulted bases } \\
\hline & Scopus & Engeneering Village & ScienceDirect & Scielo \\
\hline \multicolumn{5}{|c|}{ Used keywords and results } \\
\hline & $\begin{array}{c}\text { Research core - Bibliometric } \\
\text { analysis }\end{array}$ & \multicolumn{3}{|c|}{ Research at other bases, after Bibliometric analysis } \\
\hline $\begin{array}{c}1 \mathrm{st} \\
\text { search }\end{array}$ & $\begin{array}{c}\text { portfolio resources commitments } \\
\text { OR project portfolio management } \\
\text { OR gerenciamento } \\
\text { de portfolio - } \\
1912 \text { results }\end{array}$ & $\begin{array}{l}\text { portfolio resources commitments } \\
\text { OR project portfolio management } \\
\text { OR managing critical resources - } \\
\qquad 460 \text { results }\end{array}$ & $\begin{array}{l}\text { portfolio resources commitments } \\
\text { OR project portfolio management - } \\
233 \text { results }\end{array}$ & $\begin{array}{l}\text { project portfolio - } \\
28 \text { results }\end{array}$ \\
\hline $\begin{array}{l}\text { 2nd } \\
\text { search }\end{array}$ & $\begin{array}{l}\text { portfolio resources commitments } \\
\text { OR project portfolio management } \\
\text { OR gerenciamento } \\
\text { de portfolio - } \\
893 \text { results with constraints }\end{array}$ & $\begin{array}{l}\text { project portfolio resources - } \\
121 \text { results }\end{array}$ & $\begin{array}{l}\text { project portfolio resources - } \\
123 \text { results }\end{array}$ & $\begin{array}{l}\text { resources commitments - } \\
23 \text { results }\end{array}$ \\
\hline $\begin{array}{l}\text { 3rd } \\
\text { search }\end{array}$ & $\begin{array}{l}\text { portfolio resources commitments } \\
\text { OR project portfolio management } \\
\text { OR gerenciamento } \\
\text { de portfolio - }\end{array}$ & ..... & $\begin{array}{l}\text { portfolio resources commitments - } \\
18 \text { results }\end{array}$ & $\begin{array}{l}\text { project portfolio resources - } \\
4 \text { results }\end{array}$ \\
\hline Results & 242 results ( $3 r d$ search) & 121 results (2nd search) & 233 results (1st search) & 55 results (all searches) \\
\hline
\end{tabular}

Table 2 - Keywords

Source: Adapted from Castro (2014)

A total of 117 works of interest from other sources were added to the research, including 18 reference books, 21 internet links, 9 and 18 theses. 


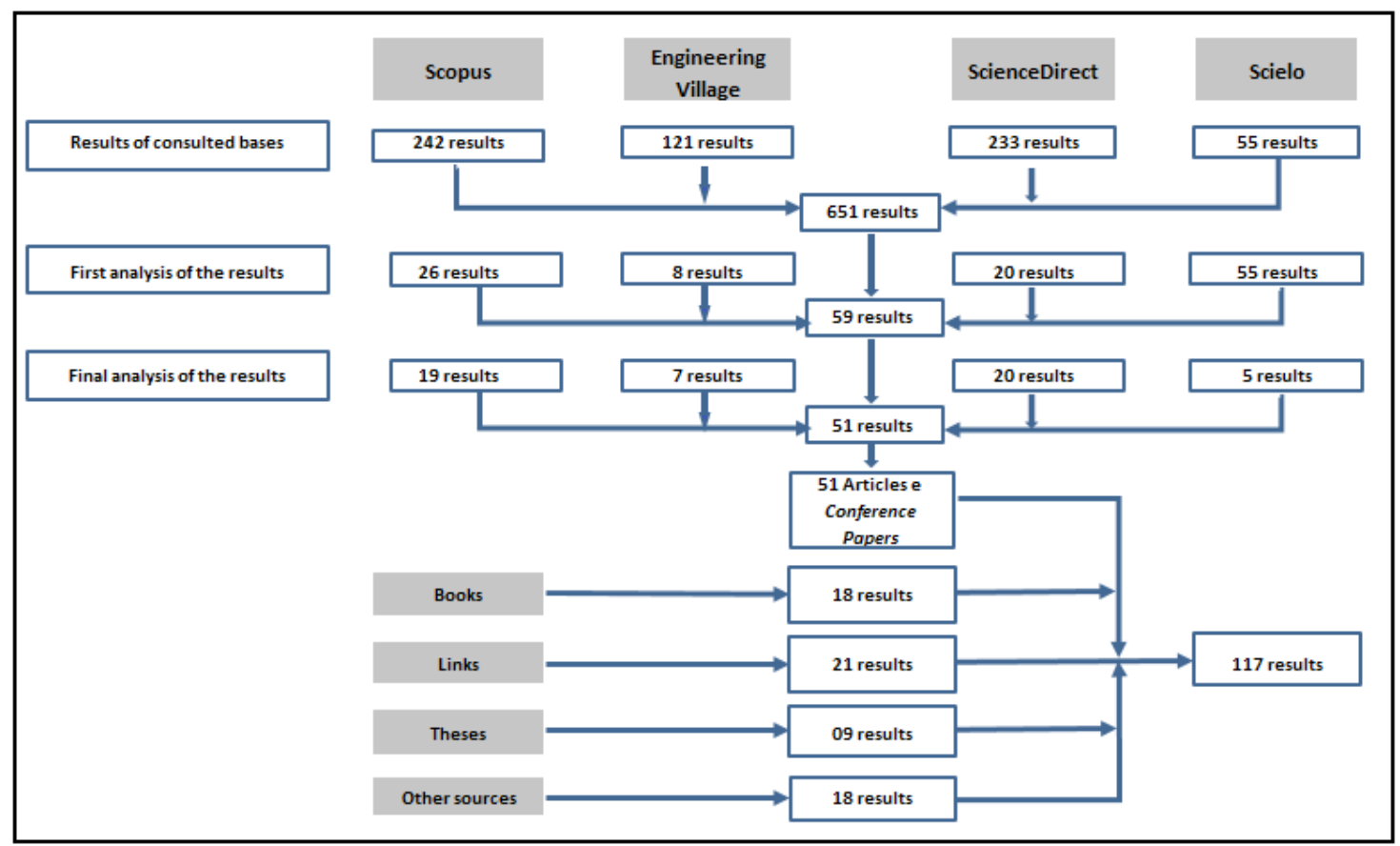

Figure 4 - Bases, books and other sources

Source: Castro (2014)

Table 3 shows the percentages of the bibliographic research. From a total of 117 results, 46 are Brazilian publications, corresponding to $39.3 \%$.

\begin{tabular}{|c|c|c|}
\hline Selection & Number & $(\%)$ \\
\hline Articles & 51 & $44 \%$ \\
Links & 21 & $18 \%$ \\
Books & 18 & $15 \%$ \\
Theses & 9 & $8 \%$ \\
Others & 18 & $15 \%$ \\
\hline Totals & 117 & $100 \%$ \\
\hline
\end{tabular}

Table 3 - Percentage of the Results from the Bibliographic Research Source: Castro (2014)

\section{RESULTS}

After following the road map presented in the Figure 2 , with a careful analysis of the publications listed in the literature, it was found that there are points of conjunction between the several principles and statements, when considering the processes studied in an isolated way. Although almost all authors have a clear understanding of the need for integration in practice, little results have been achieved accordingly. Observations in the studies that were analyzed in this survey also indicate a gap of a necessary and sufficient condition, able to bring to the conclusion that there is an ongoing integration. On the other hand, there were not statements that the integration process does not exist, since isolated business initiatives were not analyzed.

Despite the apparent distance of an integrated condition, it was possible to list 41 observations from the literature, summarized and distributed among the four processes covered by segmentation and taking as a baseline the subjects contained in the publications obtained, as well as the association of the authors with the surveyed processes.

Table 1 presents 10 statements that were chosen for the Portfolio Management. 


\section{Statements}

If a new high-priority project is added, current projects may have to be rescheduled to later dates. Management of this process involves thinking about design reuse and possible reassignment of the same engineer who worked on its forerunner.

1 [...] A single project has a well-defined scope. Multiproject management means the constant addition of new projects, possibly resulting in major changes in scope and priorities. The addition of a large multi into the workload may cause major disruption, which requires replanning that affects focus

. Olford (Why is multiple-project management hard and how can we make it easier?, 1994).

The project portfolio must have some degree of consistency and stability. In addition, although planning the portfolio once a year can be effective in practice for looking at competitive organizations, an annual review period is too long because changes in the project portfolio within a year are inevitable. The problem is that many companies do not know how to handle a more frequent portfolio review process.

. Pennypacker et Dye (Managing Multiple Projects: Planning, Scheduling and Allocating Resources for Competitive Advantage, 2002).

Insufficient resources on key projects in turn result in project teams short-cutting key activities. Cutting corners on projects results in poor information and difficulty in making sound Go/Kill decisions.

[...] Quality of information on projects is deficient. When the project team lacks the time to do a decent market study or a solid technical assessment, management is often forced to make continued investment decisions in the absence of solid information. Projects are approved that should be killed and the portfolio suffers.

. Cooper, Edgett et Kleinschmidt (New problems, new solutions: making portfolio management more effective, 2000). Difficulties associated with project portfolio selection result from several factors: a) there are multiple and oftenconflicting objectives, b) some of the objectives may be qualitative, c) uncertainty and risk can affect projects, d) the selected portfolio may need to be balanced in terms of important factors, such as risk and time completion, e) some projects may be interdependent, and f) the number of feasible portfolios is often enormous. In addition to these difficulties, due to resource limitations, there are usually constraints such as finance, work force and facilities or equipment to be considered.

. Ghasemzadeh et Archer (Project portfolio selection through decision support, 2000).

There are many different techniques that can be used to estimate, evaluate, and choose project portfolios. Some of these techniques are not widely used because they address only some of the above issues, they are too complex and require too much input data, they may be too difficult for decision makers to understand and use, or they may not be used in the form of an organized process.

. Ghasemzadeh et Archer (Project portfolio selection through decision support, 2000).

To address the problem of project portfolio management and project management, a large literature proposes classification techniques, selection and prioritization [...] However; there is a gap in the literature regarding the application of these techniques in project management of intensive national capital organizations, especially in the chemical and petrochemical sector.

. Padovani (Portfolio of projects: case study of selection and balancing, 2010). 


\begin{tabular}{|c|c|}
\hline 7 & $\begin{array}{l}\text { Most multiple project environments involve constant change, and managers should recognize that a well-defined } \\
\text { project selection and prioritization process can give guidance to project and resource managers for planning and } \\
\text { allocating resource assignments. The resource allocation issue is concerned with determining the best tradeoffs among } \\
\text { available resources throughout the duration of all projects and establishing the right priorities. } \\
\text {. Pennypacker et Dye (Managing Multiple Projects: Planning, Scheduling and Allocating Resources for Competitive } \\
\text { Advantage, 2002). }\end{array}$ \\
\hline 8 & $\begin{array}{l}\text { A new-product process, such as Stage-Gate, is a step in the right direction, but is only a partial solution. Gating } \\
\text { processes focus on individual projects and evaluate each project on its own merits. They deal with the fingers. By } \\
\text { contrast, portfolio management, by considering all projects together, looks at the fist! } \\
\text {. Cooper, Edgett et Kleinschmidt (New problems, new solutions: Making portfolio management more effective, 2000). }\end{array}$ \\
\hline 9 & $\begin{array}{l}\text { Attempts to manage multiple projects are also complicated by the fact that management attention, available } \\
\text { resources, and project control tools must be spread over many projects. These factors exacerbate and already difficult } \\
\text { task and reduce the likelihood of project success, especially when the project portfolio is composed of large and small, } \\
\text { technical and nontechnical, strategic and operational projects, among others. A multiple project environment does not } \\
\text { permit senior management attention to be focused. } \\
\text {. Pennypacker et Dye (Managing Multiple Projects: Planning, Scheduling and Allocating Resources for Competitive } \\
\text { Advantage, 2002). }\end{array}$ \\
\hline 10 & $\begin{array}{l}\text { Thus, strategy guides the split in resources across project types, between short-term and long-term projects, } \\
\text { between high-risk and low-risk initiatives, between new products and platform development versus extensions, } \\
\text { updates, and fixes. }\end{array}$ \\
\hline
\end{tabular}

Table 1 - Statements for Portfolio Management

Source: Castro (2014)

Table 2 presents 13 statements that were chosen for the Project Management.

\section{Statements}

Standards development in project management over the last decade has made a significant contribution to codification of knowledge and practices as a means of establishing the territory of a project management profession, raising its profile, and making it accessible to a wide constituency.

11

[...] The most widely known, distributed, and used guides and standards for project management are [...] indicating their general focus: projects, organizations or people. They can be further classified as either focusing on knowledge or on description of practices, the latter being primarily in the form of performance-based competency standards or frameworks intended specifically for assessment and development of project management practice in the workplace.. Morris, Pinto et Crawford (Global body of project management knowledge and standards, 2004).

Psychological and political-economic explanations better account for inaccurate forecasts. Psychological explanations account for inaccuracy in terms of optimism bias, that is, a cognitive predisposition found with most people to judge future events in a more positive light than is warranted by actual experience. Political-economic explanations, however, explain inaccuracy in terms of strategic misrepresentation.

[...] Kahneman et Tversky (1979b) argue that the prevalent tendency to underweight or ignore distributional information is perhaps the major source of error in forecasting.

. Flyvbjerg (Curbing optimism bias and strategic misrepresentation in planning: reference class forecasting in practice, 2008). 


\begin{tabular}{|c|c|}
\hline 13 & $\begin{array}{l}\text { So regardless of the strategic value of certain projects, the will of management is not exercised as to which is more } \\
\text { important in the timing of delivery to customers, internal and external. In such a situation, precedence in the access to } \\
\text { critical resources is established by individual functional managers. This is done on the basis of the degree of pressure } \\
\text { perceived and thus from a viewpoint that is, to say the least, partial. Strong political and psychological pressures are } \\
\text { among the causes of this costly situation. } \\
\text {. Pennypacker et Dye (Managing Multiple Projects: Planning, Scheduling and Allocating Resources for Competitive } \\
\text { Advantage, 2002). }\end{array}$ \\
\hline 14 & $\begin{array}{l}\text { The correct selection of a project portfolio and subsequent detailed planning should guarantee resource availability. } \\
\text { However, the unexpected changes in the duration and resource absorption of activities often force schedules to be } \\
\text { modified. Frequent conflicts between projects arise. If not resolved in a systematic perspective, these conflicts could } \\
\text { lead to a drastic reduction in performance. In spite of this widely recognized criticality, a clear and formal priority policy } \\
\text { is too often lacking: selected projects are all considered as high-priority. } \\
\text {. Maio, Verganti et Corso (A multiproject management framework for new product development, 1994). }\end{array}$ \\
\hline 15 & $\begin{array}{l}\text { The trouble is, lots of projects pass the hurdles. They are rated against objective criteria but then rarely force-ranked } \\
\text { against one another. So there is little discrimination between projects - they are all Go's! } \\
\text {.Cooper, Edgett et Kleinschmidt (New problems, new solutions: making portfolio management more effective, 2000). }\end{array}$ \\
\hline 16 & $\begin{array}{l}\text { [...] As part of their work, Kahneman et Tversky (1979a, 1979b) uncovered a systematic fallacy in planning and } \\
\text { decision-making under which people underestimate the costs, completion times, and risks of planned actions, whereas } \\
\text { they overestimate the benefits of the same actions. [...] This fallacy stems from actors taking an "inside view" focusing } \\
\text { on the constituents of the specific planned action rather than on the outcomes of similar actions already completed. } \\
\text {. Flyvbjerg (Curbing optimism bias and strategic misrepresentation in planning: reference class forecasting in practice, } \\
\text { 2008). }\end{array}$ \\
\hline 17 & $\begin{array}{l}\text { Few would disagree that the real world is not one-dimensional (one project). Rather, we are faced with a number of } \\
\text { projects competing for scares resources, narrowing windows of opportunity. [...] Projects are continually added, changed } \\
\text { and removed in response to business activity and changing market conditions. One thing is certain: the backlog of } \\
\text { needed projects requires resources that exceed management's ability to provide. Of necessity, project priority changes } \\
\text { are constant. Projects once scheduled now require schedule changes as any one of a number of parameters change. } \\
\text { Out of this seeming chaos, projects managers and resource managers are expected to create order. }\end{array}$ \\
\hline 18 & $\begin{array}{l}\text { Oil and gas production is in many ways a textbook example of the non-performance of operational plans. The range } \\
\text { of factors affecting the plan and forcing re-planning is long and unpredictable. Everything from internal events delaying } \\
\text { execution to external factors such as the weather might have an impact on the operational plan (and consequently, } \\
\text { potentially also on tactical and strategic plans). } \\
\text {. Ramstad, Halvorsen et Holte (Implementing integrated planning: organizational enablers and capabilities, 2013). }\end{array}$ \\
\hline 19 & $\begin{array}{l}\text { Organizations are trying to shorten time to market, and the functional structure tends to work counter to that. [...] } \\
\text { The matrix structure has advantages and disadvantages, which we have already discussed. } \\
\text {. Wysocki, Beck et Crane (Extentions to multiple projects, 2000). }\end{array}$ \\
\hline
\end{tabular}




\begin{tabular}{|c|c|}
\hline 20 & $\begin{array}{l}\text { The matrix structure, or some hybrid of it, is the preferred organizational form for planning and controlling multiple } \\
\text { projects. The pure project structure greatly simplifies resource scheduling, but it is easily seen as a very inefficient } \\
\text { resource utilization [...] and no formal mechanism exists to share excess capacity with other projects. The resulting cost } \\
\text { inefficiencies are obvious. [...] The matrix form is generally preferred in those organizations in which projects are an } \\
\text { important component of departmental activity and where change and adaptability are expected. } \\
\text {.Wysocki, Beck et Crane (Extentions to multiple projects, 2000). }\end{array}$ \\
\hline 21 & $\begin{array}{l}\text { A single project has a well-defined scope. Multiproject management means the constant addition of new projects, } \\
\text { possibly resulting in major changes in scope and priorities. The addition of a large multi into the workload may cause } \\
\text { major disruption, which requires replanning that affects focus } \\
\text {. Olford (Why is multiple-project management hard and how can we make it easier?, 1994). }\end{array}$ \\
\hline 22 & $\begin{array}{l}\text { However, most individuals and organizations are inclined to adopt the inside view in planning new projects. This is } \\
\text { the conventional and intuitive approach. The traditional way to think about a complex project is to focus on the project } \\
\text { itself and its details, to bring to bear what one knows about it, paying special attention to its unique or unusual features, } \\
\text { trying to predict the events that will influence its future. The thought of going out and gathering simple statistics about } \\
\text { related projects seldom enters a planner's mind. } \\
\text {. Flyvbjerg (Curbing optimism bias and strategic misrepresentation in planning: reference class forecasting in practice, } \\
\text { 2008). }\end{array}$ \\
\hline 23 & $\begin{array}{l}\text { As Goldratt (1997), the uncertainties inherent in the projects are the main source of problems in project management. } \\
\text { They stem from difficulties and obstacles difficult to predict at the beginning of the project that unknown and } \\
\text { immeasurable at that time, become a problem for the project planning, especially in the activity duration estimates. } \\
\text { To compensate uncertainties, time estimates of the activities are inflated, adding security. Goldratt (1997) presents } \\
\text { three mechanisms that influence the increase in the activities duration estimates: a pessimistic experience, [...] levels } \\
\text { of management and [...] the possible cuts. }\end{array}$ \\
\hline
\end{tabular}

Table 2 - Statements for Project Management

From: Castro (2014)

Table 3 presents 5 statements that were chosen for the Operations Management.

\section{Statements}

\begin{tabular}{|l|l|}
\hline \multicolumn{2}{|c|}{ Statements } \\
\hline 24 & $\begin{array}{l}\text { Coupling day-to-day planning to the strategic business plan in this medium-term resource allocation is absolutely } \\
\text { necessary. Also, by linking medium-term resource allocation and day-to-day resource planning to long-term resource } \\
\text { allocation, the business strategy process, and strategic goal, all affected stakeholders will have a better understanding } \\
\text { of the overall need for a logical and consistent project selection and prioritization and, in effect, a reliable resource } \\
\text { allocation process. }\end{array}$ \\
\hline 25 & $\begin{array}{l}\text { Data from the three oil \& gas companies showed that the planning process in general was particularly complicated } \\
\text { due to the extensive use of different planning tools throughout the industry. The main problem, however, is not the } \\
\text { variety of tools, but the lack of harmonization between them. The tools available rarely allow for automatic interchange } \\
\text { of data. } \\
\text {. Ramstad, Halvorsen et Holte (Implementing integrated planning: organizational enablers and capabilities, 2013). }\end{array}$ \\
\hline
\end{tabular}




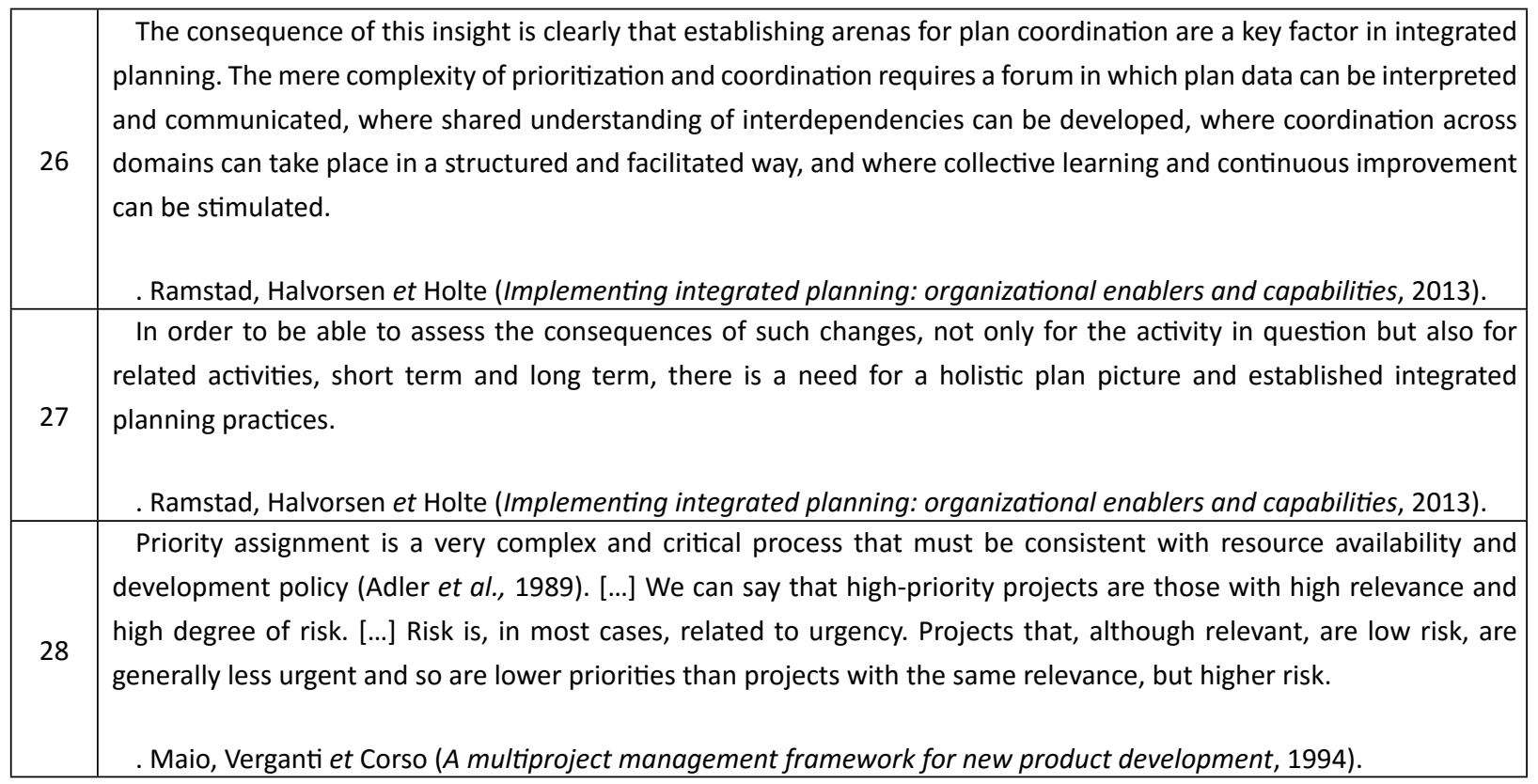

Table 3 - Statements for Operations Management

From: Castro (2014)

Finally, Table 4 presents 13 statements that were chosen for the Resources Management.

\section{Statements}

If a resource divides her attention between different tasks before handing off task deliverables, all the projects involved will take longer than necessary, because all of that resource's successors from each project will have to wait longer than necessary because of time spent on other project work. If many resources in the organization become accustomed to working in this manner, then most projects will take significantly longer than necessary, in both their promise and their execution. The projects will also be affected by the variability of not only their own tasks, but also of

29 those associated with the other projects that are interleaved within them.

One of the key challenges of multiproject or program management, therefore, revolves around the avoidance of pressures on resources to multitask and the ability to assess and direct the most beneficial use of resources when there is apparent contention for their attention.

Patrick (Turning many projects into few priorities with theory of constraints, 1999).

The fact is that most project selection and portfolio management methods do a poor job of resource balancing. Projects are evaluated, Go decisions are made, but resource implications are often not factored in. [...] Management is presented with the NPV of the projects, along with probability distribution curves. These same models [...] are notably 30 lacking in their handling of the resource constraint problem, as resource availability is rarely part of the financial calculation.

Cooper, Edgett et Kleinschmidt (New problems, new solutions: making portfolio management more effective, 2000). The problem of too many projects and too few resources can be partly resolved by undertaking a resource capacity analysis. This analysis attempts to quantify your projects' demand for resources. [...] Resource capacity analysis is

31 a tactical move, but it is relatively straightforward and provides real insights into the nature and magnitude of the resource constraint problem, 
\begin{tabular}{|l|l}
\hline 32 & $\begin{array}{l}\text { Unique capabilities of a company sustain strategic competitive advantages. } \\
\text {. Wright, Kroll e et Parnell (Administração estratégica: conceitos, 2009). }\end{array}$ \\
\hline
\end{tabular}

As some researchers have noted, the major reason why some projects are selected but not completed is that resource limitations are not always formally included in the project selection process. In cases where resource limitations are at fault for a failed project, a selection model that incorporated resource limitations could have aided the decision maker

33 in avoiding such mistakes. Portfolio selection becomes more complex when resources availability and consumption are not uniform over time.

. Ghasemzadeh et Archer (Project portfolio selection through decision support, 2000).

Periodic reviews of current and potential projects to be placed in the project portfolio, as well as decisions regarding resource allocation must be conducted. Without quarterly, or at least semiannual, evaluations, decisions on the makeup of the project portfolio are generally made too late and, because of pressure to be "productive", resource allocation 34 decisions are solved in discussions between project managers and resource managers.

. Pennypacker et Dye (Managing Multiple Projects: Planning, Scheduling and Allocating Resources for Competitive Advantage, 2002).

Inadequate resources and poor information invariably lead to a tendency to do short-term, quick, and simple projects. And so the portfolio problems continue, feeding one another in an endless downward spiral.

35

[...] Lack of resources is part of the problem. The other part is the failure to allocate resources effectively. Here, portfolio tools and methods are partly at fault, along with a lack of will on the part of senior management to cut back the number of active projects, to say "no" to some worthwhile initiatives.

. Cooper, Edgett et Kleinschmidt (New problems, new solutions: making portfolio management more effective, 2000). [...] A clear and formal project selection prioritization policy is often lacking; selected projects are all considered as high-priority projects. As a result, there is no clear guidance as to which project(s) has the greater urgency and the

36 more critical need for resources, effectively placing all projects in an equally competitive position for limited resources.

. Pennypacker et Dye (Managing Multiple Projects: Planning, Scheduling and Allocating Resources for Competitive Advantage, 2002).

In an effort to take advantage of valuable new opportunities, multiproject organizations tend to launch projects as soon as they are understood - concurrently with existing projects, simultaneously with other new efforts, and unfortunately, too often without sufficient regard for the capacity of the organization. A common result is that the responsibility for sorting out an array of conflicting priorities often falls to project resources and their managers. One 37 concern coming from this situation is that the resultant locally set priorities may not be in synch with each other or, more importantly, to deal with this tug-of-war of multiple priorities is the practice of multitasking, that is, assigning resources to more than one significant task during a particular window of time, to try to move all the projects along.

. Patrick (Turning many projects into few priorities with theory of constraints, 1999).

Many project teams rely on early starts of projects and their paths of tasks to try to achieve timely project completion. These early starts, also driven partially by the desire to see "progress" on all open projects, often translate to additional pressure on resources to multitask between both tasks and projects. There is pressure to get started on a new task in the inbox, even though we're still working on another task. As a result, these practices of early starts and multitasking 38 have been recognized as common practice in many organizations and even institutionalized in project management software tools, which typically default to "asap" scheduling, and which offer "features" to apply fractional resources to tasks and to split tasks. 


\begin{tabular}{|l|l|l|}
\hline 39 & $\begin{array}{l}\text { When faced with assessing system capacity, many organizations typically go into a major data-collection and number- } \\
\text { crunching exercise in an attempt to balance the availability of all resource types with the demand on the system. } \\
\text { To support the scheduling and monitoring of projects, however, the required process is far simpler than that usual } \\
\text { approach. }\end{array}$ \\
\hline 40 & $\begin{array}{l}\text { Multiproject management of portfolio, in particular, is one of the points at which traditional methods and techniques } \\
\text { appear to be less adequate. This problem is mainly related to the complexity of interproject links. Within this context, } \\
\text { the modelization of the input/output interdependencies between projects and their integration within an explanatory } \\
\text { framework that also considers resource interdependencies is intended as a first step toward the development of more } \\
\text { comprehensive support systems. }\end{array}$ \\
\hline 41 & $\begin{array}{l}\text { Real problems have been observed within a number of companies attempting to implement the consolidation } \\
\text { model. These include Complexity, [...] Timing, [...] Consistency, [...] Organization fit, [...] Interaction with resources, [...] } \\
\text { Nonproject work and [...] Part-time and intermittent assignments. }\end{array}$ \\
. Geoff Reiss (Multiproject scheduling and management, 2000).
\end{tabular}

Table 4 - Statements for Resources Management

\section{RESULTS}

The following conclusions are based on the Bibliographic Panel above, which was based on the selected publications in the bibliometric analysis and bibliographic research.

\section{PORTFOLIO MANAGEMENT}

There is not a good visibility for the integrated planning, neither for the appropriate allocation of resources in the medium and long term. This situation becomes more critical when there is the insertion or withdrawal of portfolio projects, generating changes in the timing of projects, frequent rework and weakness in the allocation. In this case, a guideline to follow is to allow updates in the near term to be considered in the medium and long term, where all the planning horizons must be connected and integrated. But this is still not a reality in the analyzed segment.

Considering the vision of portfolio, there is a vast literature on selection and prioritization techniques, though few focused on the area of oil and gas. Even with them, there are complexities, lack of flexibility and low interaction with all stakeholders. Therefore, it was not found a widely recommended method of unrestricted use with standard tools. Additionally, there are many non-consolidated information brought to the portfolio, where issues of resource constraints are not usually considered.

\section{PROJECT MANAGEMENT}

With respect to the project management, it was clear that the practices and procedures are well-established on individual projects, which usually look for good attractiveness rates, with the benefits sometimes overestimated. In some texts, it was observed that there was little use of statistical and historical data of projects already implemented in new ventures. There is, however, a preference for internal and individual insights of each project. In other words, new projects mostly are presented with good indicators, bringing a new and original concept, but neglecting the lessons learned from similar projects already implemented. Thus, costs, durations and risks are often underestimated. Another important point is that the projects are rarely confronted against each other, with little discrimination between them. This, within steps of prioritization and selection, just inducing the adoption of virtually all ofth.

It is a common point in the literature that the uncertainties inherent to the projects are the main source of problems. To minimize this, there is increasing durations, often absorbing more resources than necessary, generating conflicts between the projects and programming changes. It was also reported that changes in the priorities of the projects is a usual practice, the result of a permanent competition for scarce resources. As a result, they are changed, removed or added, mainly in portfolio reviews. Duration increases, programming and priorities change are factors that generate delays, requiring resources above the organizational capacity to provide them.

Finally, it was observed that the matrix structure is preferred for the implementation of large projects, however it is seen as inefficient in the use of surplus resources. It has featured in the organizations where the projects are important business components and where changes are 
frequent. In these structures, there are difficulties in the assignment or transfer to other projects when resources have lounges.

\section{OPERATIONS MANAGEMENT}

Not only in projects, but also in the operations, it is known that the internal and external events delay the activities and impact on programming, especially in the oil and gas industry, leading to an ongoing review, even while execution. The effects of reprogramming are not entirely clear and are difficult to assess and quantify, especially in the medium and long term. It was observed in the literature that the integration between the day-to-day programming and annual planning and the multiannual should be deployed, in order to have coherence between the selection and prioritization defined in the portfolio and the correct allocation of resources. In other words, the integration of horizons in the short, medium and long term is an aspiration of those who work with planning, though no evidence was found that this integration is underway. The status of integration is even more critical if looked at the point of view of operation and projects management, making the goal of integration to be pursued in many organizations.

It was found that the projects of operating range, which are considered of lower risk and less urgent, they lose often the priority when compared with projects involving large investments, considered high risk and greater urgency.

\section{RESOURCE MANAGEMENT}

In the studied literature, it can be seen that the organizational pressures are constant and act on virtually all activities and especially on resources, often shared among competing priorities, creating delays. In an attempt to minimize these delays, many organizations make use of the multitasking, by dividing tasks and sharing resources. The effect often measured is the delay in the critical paths and earlier deadlines of the projects involved in the sharing.

Looking at the resources management in a longterm perspective, a point that must be highlighted is the mathematical modeling to analyze the resource capacity of a company, which is one way to quantify the balance between the supply of resources and the demands of activities by facilitating long-term business processes. Equally important is the modeling of interdependencies between projects and resources. This is also an important tool to support longterm business strategies.

Still considering the mathematical modeling, it was observed that some methodologies that consider the economic viability of the projects are in need of feasibility studies and resource constraints. A major cause for some selected projects are not completed within agreed deadlines is the limitation of resources, which is not formally considered in the selection processes and prioritization of the portfolio.

There was not a methodology structured to reallocate the resources whenever there are revisions on the project portfolio. The existing ones are weak, with decisions made often between the resource and project managers, without a more comprehensive and business-minded perspective.

\section{CONCLUSIONS}

From what was presented at the Bibliographic Panel, it appears that formal regular meetings with program and planning managers, the use of integrated software tools, integrated processes, as well as prepared teams are success factors for the interfaces between portfolio, projects, production operations and resource allocation to add value to an organization.

There was no evidence approaches to integrated management, involving projects, portfolio, production operation and resources or their interfaces, in the literature, regarding the four cases considered, even where they occur, when it relates to companies with portfolios of multiple and large projects.

There are several references, but isolated, on what should be implemented, like best practices in the organizations, in order to improve integration. Among them, it is possible to mention the control of the most critical items, consistency between short, medium and long-term, operational demands considered together with the project demands, contracting strategies associated with the process of portfolio prioritization, among others. However, it was not observed a case where they have successfully taken place.

Despite the high number of respondents authors, the problems described at the interfaces between processes, the few quotes about a wide integration and the wide scope, due to the existing multidisciplinary, seem to indicate a consensus. This, however, is only a perception. Further research should be done in the search for a better understanding of these issues.

Regarding the proposed objective, it is concluded that this research has managed to build an update bibliographic panel on the studied processes, based on the reflections from thematic approaches published in books, journals and academic databases.

\section{REFERENCES}

Associação Brasileira de Normas Técnicas. NBR 6023: informação e documentação - referências - elaboração. Rio de Janeiro, (2002); 
Castro, J. F. T. Proposta de metamodelo de gestão integrada: Alocação de recursos para atendimento a portfólio de projetos e de operações. Estudo de caso na indústria de óleo e gás. Dissertação de mestrado, LATEC/UFF (2014);

Cooper, R. G., Edgett S. J., Kleinschmidt, E. J. New problems, new solutions: making portfolio management more effective. Research Technology Management 43 (2000) 18-33;

Costa, H. G.; Costa, E. C.; Carvalho, R. A.; Gutierrez, R. H. Mapeamento de lacunas de percepções no negócio de e-procurement sobre o desempenho organizacional. Revista Dirección y Organización, n. 47, p. 62-69, 2012;

Costa, H. G. Modelo para Webibliomining: proposta $e$ caso de aplicação. Revista da FAE, v. 13, p. 115-125, 2010;

Da Silva, E.M. et al. Critical Chain of the Theory of Constraints applied to Executive Engineering Project Management: A case study in a petroleum refinery. Gestão e Produção 19 (1). Pp 1-16. (2012) ISSN 0104-530X;

Flyvbjerg, B. Curbing optimism bias and strategic misrepresentation in planning: reference class forecasting in practice. European Planning Studies 16:1 (2008) 3-21;

Ghasemzadeh, F. et al. Project portfolio selection through decision support. Decision Support Systems 29 (1). Pp. 7388. (2000). ISSN 0167-9236;

Gil, Antônio Carlos. Como elaborar projetos de pesquisa. 5a Edição, São Paulo, Atlas, (2010);

Gil, A. C. Métodos e Técnicas de Pesquisa Social, 6ạ Edição, São Paulo, Atlas, (2011);

Guia PMBOK, Um guia de conhecimentos em gerenciamento de projetos. 3.a Ed. Pennsylvania: PMI, (2004);

Gutierrez R. H. Estratégias de Negócios. Draf, apostila de aula. Rio de Janeiro, 2010;

Maio, Adriano D., Verganti, R., Corso, M. A multi-project management framework for new product development. European Journal of Operational Research 78 (1994) 178191;

Marconi, Marina de A., Lakatos, Eva M. Metodologia Científica. 6a Edição, São Paulo, Atlas, (2011);

Marconi, Marina de A., Lakatos, Eva M. Fundamentos de Metodologia Científica. 5a Edição, São Paulo, Atlas, 2003;

Morris, P. W. G., Pinto J. K., Crawford L. Global Body of Project Management Knowledge and Standards. John Wiley \& Sons, Inc. (2004);

Olford, J. O. Why is multiple-project Management hard and how can we make it easier? Adaptado de Proceedings of the Project Management Institute: Seminars and Symposium. Newark, New Jersey, USA, (1994);

Padovani, M. et al. Portfolio of projects: Case study of selection and balancing. Gestão e Produção 17 (1). Pp 157180. (2010). ISSN 0104-530X;

Patrick, F. S. Program Management - Turning many projects into few priorities with theory of constraints. Focused Performance, Hillsborough, New Jersey, USA (1999);

Pennypacker, J. S., Dye, L. D. Managing Multiple Projects: Planning, Scheduling and Allocating Resources for Competitive Advantage. Pennsylvania, CBP, (2002);

Ramstad, L. S.; Halvorsen, K.; Holte, E. A. Implementing Integrated Planning: Organizational Enablers and Capabilities. Extraido de Integrated Operations in the Oil and Gas Industry: Sustainability and Capability Development. (2013). BSR IGI Global. Hershey PA, USA Pp. 171-190;

Reiss G. Multiproject Scheduling and Management. Adaptado de Programme Management Website, www.eprogramme.com, (2000);

Revista FAE - Costa, H.G. Modelo para Webibliomining: proposta e caso de aplicação. v. 13, p. 115-125, 2010;

Valle, L. A.; Gutierrez, R. H.; Costa, H. G. Estudo Bibliométrico da Produção Científica em Gestão de Processos na Saúde no Brasil. Congresso Nacional de Excelência em Gestão - Enegep, (2013);

Vergara, S. C. Projetos e relatórios de pesquisa em administração, 13a Edição, São Paulo, Atlas, (2011);

Wright, P., KROLL, M. J., PARNELL, J. Administração Estratégica: conceitos. São Paulo: Atlas, (2009);

Wysochi, R. K.; Beck R. J.; Crane D. B. Extentions to Multiple Projects. Adaptado de Effective Project Management (2000);

Yin, Robert K. Estudo de caso: planejamento e métodos, 2a Ed., Porto Alegre: Bookman, (2001). 